\title{
SLAMs Negatively Regulate IL-2I Production in Tfh-Like Cells from Allergic Rhinitis Patients
}

This article was published in the following Dove Press journal:

Journal of Asthma and Allergy

\author{
Jun Yang' \\ Lina Geng ${ }^{2}$ \\ Yongmin $\mathrm{Ma}^{3}$ \\ Xinyi Tang' \\ Huiyong Peng' \\ Jie $\operatorname{Tian}^{2}$ \\ Huaxi $X u \mathbb{D}^{2}$ \\ Shengjun Wang $\mathbb{D}^{1,2}$ \\ 'Department of Laboratory Medicine, \\ The Affiliated People's Hospital, Jiangsu \\ University, Zhenjiang, People's Republic \\ of China; ${ }^{2}$ Institute of Laboratory \\ Medicine, Jiangsu Key Laboratory for \\ Laboratory Medicine, Jiangsu University \\ School of Medicine, Zhenjiang, People's \\ Republic of China; ${ }^{3}$ Department of \\ Otorhinolaryngology-Head Surgery, The \\ Affiliated People's Hospital, Jiangsu \\ University, Zhenjiang, People's Republic \\ of China
}

Background: Allergic rhinitis (AR) is characterized by type I hypersensitivity that is mediated by IgE-induced humoral responses. Follicular helper T cells (Tfh) comprise the key helper $\mathrm{T}$ cell $(\mathrm{Th})$ subset that promotes antibody production. Signaling lymphocytic activation molecules (SLAMs) participate in regulation of the differentiation and function of $\mathrm{Tfh}$ cells, but whether this regulation is involved in the pathogenesis of AR is unknown.

Methods: CD4+CXCR5+ Tfh-like cells from peripheral blood were detected by flow cytometry. The IL-21 and IgE levels in serum were measured by an ELISA. Blood CD4 +CXCR5+ Tfh-like cells were sorted and cultured with anti-SLAM mAb in vitro.

Results: The frequencies of circulating CD4+CXCR5+ Tfh-like cells appeared virtually unchanged in AR patients, but the expression of SLAMs and SLAM-associated protein (SAP) on circulating Tfh-like cells was significantly decreased. Meanwhile, the level of serum IL-21 was increased in AR patients, and a negative correlation was found between the IL-21 level and SLAM or SAP expression on CD4+CXCR5+ T cells. Treatment with antiSLAM mAb resulted in reduced IL-21 production by Tfh-like cells in vitro. Additionally, SLAM expression on B cells was significantly decreased, although the percentages of B cells were increased in AR patients.

Conclusion: SLAMs negatively regulate IL-21 production in CD4+CXCR5+ Tfh-like cells, which contributes to the pathogenesis of AR.

Keywords: AR, circulating Tfh-like cells, SLAM, IL-21

\section{Introduction}

Allergic rhinitis (AR) is one of the most common upper respiratory diseases and is characterized by the clinical symptoms of sneezing, pruritis, nasal congestion, and rhinorrhea. AR is also characterized by type I hypersensitivity mediated by IgE. The imbalance between the Th1 and Th2 immune responses plays a significant role in AR. The proportion of Th2 cells and the Th2 cytokine levels are increased, including the level of IL-4, a switch factor for IgE, and IL-5, an eosinophil growth factor. ${ }^{1,2}$ According to recent studies and advances in the understanding of the mechanisms of AR, other subsets of $\mathrm{CD}^{+} \mathrm{T}$ cells and related cytokines participate in the pathologic process of AR, including IL-17-producing Th17 cells ${ }^{3}$ and follicular helper $\mathrm{T}$ cells $(\mathrm{Tfh}){ }^{4}$

Tfh cells have been described as a new subset of $\mathrm{CD}^{+} \mathrm{T}$ helper cells (Th) that Department of Laboratory Medicine, The Affiliated People's Hospital, Jiangsu

University, No. 8, Dianli Road, Zhenjiang, 212002, People's Republic of China

Tel +86-5II-889I-5573

Fax+86-5II-8503-8483

Email sjwjs@ujs.edu.cn can substantially assist B cells. A distinguishing feature of Tfh cells is their high expression levels of CXCR5, programmed cell death protein (PD-1), inducible costimulator (ICOS), and transcription factor (Bcl-6). IL-21 is the most effective cytokine secreted by Tfh cells. ${ }^{5}$ Tfh cells participate in the formation and 
maintenance of the germinal center (GC), where the processes of B cell affinity maturation, class switch recombination, plasma cell differentiation and memory B cell differentiation predominantly occur. IL-21 is a major cytokine that is important for optimal GC B cell proliferation ${ }^{6}$ and can potently drive plasma cell differentiation in both humans and mice through the activation of STAT3. ${ }^{7-9}$ Recently, Morita et al found that $\mathrm{CD}^{+} \mathrm{CXCR} 5^{+} \mathrm{T}$ cells in human blood shared markers with GC Tfh cells and could induce the differentiation of naive $B$ cells into plasmablasts via IL-21, which suggested that peripheral blood $\mathrm{CD}^{+} \mathrm{CXCR}^{+} \mathrm{T}$ cells may represent the circulating compartment of Tfh-like cells. ${ }^{10}$ Many studies have focused on circulating Tfh cells and have indicated that they are produced in autoimmune diseases, such as rheumatoid arthritis, systemic lupus erythematosus, and Graves' disease and are related to serum autoantibodies. ${ }^{11,12}$

Signaling lymphocytic activation molecule (SLAM) is a transmembrane protein and a cell surface glycoprotein expressed on immune cells, such as $\mathrm{T}$ and B lymphocytes and dendritic cells. SLAM is a self-ligand that can promote the interaction between $\mathrm{T}$ cells and $\mathrm{B}$ cells or other antigen-presenting cells (APCs) that express SLAMs. ${ }^{13}$ SLAM-associated protein (SAP) is a type of intracellular adapter protein that can bind to the immunoreceptor tyrosine-based switch motif (ITSM) present in the cytoplasmic portion of SLAM to deliver the signal. ${ }^{14}$ SAP functions in the full polarization stage of Tfh cells and is indispensable for GC Tfh cell development. ${ }^{15,16} \mathrm{GC}$ Tfh cells express high levels of SAP. SAP deficiency can cause human X-linked lymphoproliferative disease (XLP), which is characterized by impaired GC formation and antibody responses. ${ }^{17,18}$ SLAM and SAP play critical roles in Tfh cell development and function. First, SAP is required for the formation and maintenance of T-B conjugates ${ }^{16}$ through SLAM self-combination, which can regulate the capability of Tfh cells to assist GC B cells. Second, SAP may modulate the crosstalk between SLAMs and $\mathrm{T}$ cell receptors (TCRs) ${ }^{19,20}$ by engaging with APCs (B cells). Third, SLAM has been reported to induce GC Tfh cells to synthesize IL-4 through SAP in a Th2-independent manner, suggesting the important role of SLAM in the regulation of cytokine expression in Tfh cells. ${ }^{21}$

Given the pivotal role of Tfh cells in humoral immunity, it is worth determining whether $\mathrm{CD} 4^{+} \mathrm{CXCR} 5^{+} \mathrm{Tfh}-$ like cells and SLAM/SAP in Tfh cells are involved in the progression of AR, which is an immune disorder accompanied by high levels of IgE. We documented that the decreased SLAM expression on $\mathrm{CD}^{+} \mathrm{CXCR}^{+} \mathrm{T}$ cells might upregulate IL-21 expression, which may be involved in the pathogenesis of AR.

\section{Methods}

\section{Individuals and Samples}

Twenty-two patients with AR, including 7 males and 15 females, who were treated in the Department of Otorhinolaryngology-Head Surgery were included in this study. The diagnosis of AR was based on the commonly accepted clinical criteria and a positive allergen test result. The clinical symptom included nasal congestion, nasal drainage, sneezing, itching and pale nasal mucosa. None of the patients were being treated with oral or topical therapy. Twenty healthy subjects who exhibited no symptoms or history of allergic diseases were included as controls. Peripheral venous blood samples were obtained from all patients and healthy controls. The serum IgE levels were measured and found to be significantly higher in AR patients than in healthy controls $(\mathrm{p}<0.05)$. The characteristics of the patients and controls are shown in Table 1. Allergen tests results are shown in Table 2. This study was approved by the ethics committee of the Affiliated People's Hospital of Jiangsu University, and the study was conducted in accordance with the declarations of Helsinki. Patients gave written informed consent prior to collection of their blood specimens.

\section{Cell Isolation and Purification}

Peripheral blood mononuclear cells (PBMCs) were isolated by density-gradient centrifugation with FicollHypaque solution (Haoyang Biological Technology Co, Tianjin, China). $\mathrm{CD}^{+} \mathrm{T}$ cells were isolated from PBMCs through immunomagnetic cell sorting using negative selection kits, and $\mathrm{CXCR}^{+}$cells were purified from $\mathrm{CD}^{+} \mathrm{T}$ cells by FITC-conjugated anti-human CXCR5 $\mathrm{mAb}$ and anti-FITC microbeads (Miltenyi Biotec $\mathrm{GmbH}$,

Table I Clinical Features of AR Patients and Healthy Controls Included in the Study

\begin{tabular}{|l|c|c|}
\hline & AR & HC \\
\hline N & 22 & 20 \\
Gender(M/F) & $7 / 15$ & $8 / 12$ \\
Age $(\mathrm{yr})$ & $34.43 \pm 2.820$ & $30.94 \pm 3.265$ \\
lgE $(\mathrm{ng} / \mathrm{ml})$ & $319.1 \pm 70.03 *$ & $144.8 \pm 5.729$ \\
\hline
\end{tabular}

Notes: Data represent the arithmetic mean \pm SD. ${ }^{*} p<0.05$. Abbreviations: $M$, male; $F$, female. 
Table 2 Information of AR Patients in the Study

\begin{tabular}{|c|c|c|c|c|}
\hline Patient & Sex & Age & Allergen Test Result & Total IgE (ng/mL) \\
\hline ARI & Female & 29 & House dust mite:++ & 248.52 \\
\hline AR2 & Female & 40 & Tree combination:+ & |34.7| \\
\hline AR3 & Male & 15 & House dust mite+++ & 520.07 \\
\hline AR4 & Male & 26 & House dust mite:+++ & 296.7 \\
\hline AR5 & Female & 24 & House dust mite:+++ & 303.48 \\
\hline AR6 & Female & 59 & House dust:+; cockroach:+; fungus:+ & 131.59 \\
\hline AR7 & Female & 25 & House dust mite:+ & 151.78 \\
\hline AR8 & Male & 40 & Cockroach:+ & 126.55 \\
\hline AR9 & Female & 19 & House dust mite:+++ & 515.12 \\
\hline ARIO & Female & 32 & House dust: + & 140.19 \\
\hline ARII & Female & 52 & Shot ragweed:++++; artemisia:+++; tree combination:++++ & 534.12 \\
\hline ARI2 & Female & 17 & House dust mite:+++++; house dust:++; cockroach:++ & 1029.16 \\
\hline ARI3 & Female & 26 & House dust mite:+; dog epithelium:++++; cat hair:+ & 234.41 \\
\hline ARI4 & Male & 49 & House dust mite:+++++; house dust:+; cockroach:+ & 1428.2 \\
\hline ARI5 & Female & 25 & House dust mite:+; cockroach:+ & 140.19 \\
\hline ARI6 & Male & 41 & House dust mite:++ & 175.55 \\
\hline ARI7 & Female & 54 & House dust mite:+ & 131.12 \\
\hline ARI8 & Female & 22 & Cockroach: ++ & 223.66 \\
\hline ARI9 & Female & 38 & House dust mite:+ & 152.1 \\
\hline AR20 & Male & 24 & House dust: + & 134.46 \\
\hline AR2I & Female & 29 & House dust mite:+ & 133.49 \\
\hline AR22 & Male & 49 & House dust mite:+ & 135.46 \\
\hline
\end{tabular}

Notes: +: $0.35 \mathrm{kU} / \mathrm{L}<\operatorname{sgg}<0.7 \mathrm{kU} / \mathrm{L} ;++$; $0.7 \mathrm{kU} / \mathrm{L}<\operatorname{sgE}<3.5 \mathrm{kU} / \mathrm{L} ;+++: 3.5 \mathrm{kU} / \mathrm{L}<\operatorname{sgg}<17.5 \mathrm{kU} / \mathrm{L} ;++++$ : $17.5 \mathrm{kU} / \mathrm{L}<\operatorname{slgE}<50 \mathrm{kU} / \mathrm{L} ;+++++$ : $50 \mathrm{kU} / \mathrm{L}<\mathrm{slgE}<100$ $\mathrm{kU} / \mathrm{L}$.

Bergisch Gladbach, Germany) according to the manufacturer's instructions.

\section{$\mathrm{CD}^{+} \mathrm{CXCR}^{+} \mathrm{T}$ Cell Culture and}

\section{Stimulation}

Ninety-six-well cell culture plates were precoated with 0.5 $\mu \mathrm{g} / \mathrm{mL}$ monoclonal anti-CD3 (Miltenyi Biotec $\mathrm{GmbH}$ ) for $2 \mathrm{~h}$ at $37^{\circ} \mathrm{C}$. First, the sorted $\mathrm{CD} 4^{+} \mathrm{CXCR} 5^{+}$cells $\left(1 \times 10^{5} /\right.$ well) were cultured in RPMI 1640 medium supplemented with $10 \%$ FBS and anti-SLAM or control IgG (BioLegend, San Diego, CA) for the indicated times at $37{ }^{\circ} \mathrm{C}$ in $5 \% \mathrm{CO}_{2}$. Second, $50 \mathrm{ng} / \mathrm{mL}$ phorbol myristate acetate (PMA) and $1.0 \mu \mathrm{g} / \mathrm{mL}$ ionomycin (Sigma-Aldrich St. Louis, MO) were added to the cell culture plates for 5 $\mathrm{h}$. Then, the supernatants were collected, and IL-21 was detected by ELISA.

\section{ELISA}

IL-21 in cell culture supernatant or serum and $\operatorname{IgE}$ in serum were detected by ELISAs according to the manufacturer's instructions (eBioscience, San Diego, CA).

\section{Flow Cytometry}

Cells were washed and immunostained with phycoerythrin (PE)-Cy5-conjugated anti-CD3, PE-conjugated antiSLAM, PE-conjugated anti-SAP (eBioscience, San Diego, CA), allophycocyanin-conjugated anti-CD4, FITCconjugated anti-CD19 (BioLegend, San Diego, CA), and Alexa Fluor 488-conjugated anti-CXCR5 (Becton Dickinson, San Jose, CA) mAbs against the human cell surface. Isotype-matched $\mathrm{Ab}$ controls were used in all procedures. The entire staining process was performed according to the manufacturer's protocol. The stained cells were analyzed on a FACSCalibur flow cytometer with CELLQUEST software (Becton Dickinson, Sparks, MD).

\section{Statistics}

Statistical significance was determined by an unpaired $t$-test (two-tailed with an equal SD), and correlations between variables were determined by calculation of Spearman correlation coefficient. All data were analyzed with GraphPad Prism 8.0 software (GraphPad Software, Inc., San Diego, CA). A p-value $<0.05$ was considered statistically significant. 


\section{Results}

Decreased SLAM and SAP Expression on Circulating Tfh-Like Cells in AR Patients

First, we investigated the percentages of circulating Tfhlike cells in AR patients. However, there were no significant differences in the frequencies of $\mathrm{CD}^{+} \mathrm{CXCR} 5^{+}$ $\mathrm{T}$ cells in the peripheral blood in AR patients compared with those in healthy controls (Figure 1A-C).

Next, we focused on SLAM and the adapter protein SAP, which are important for Tfh cell development.
Compared with that in healthy individuals, SLAM (Figure 1D-F) and SAP (Figure $1 \mathrm{G}$ and $\mathrm{H}$ ) expression on $\mathrm{CD}^{+} \mathrm{CXCR}^{+} \mathrm{T}$ cells was lower in $\mathrm{AR}$ patients as detected by flow cytometric analysis. Meanwhile, a positive correlation between SLAM and SAP expression in $\mathrm{CD}^{+} \mathrm{CXCR}^{+} \mathrm{T}$ cells from AR patients (Figure 1F) suggested that the SLAM and SAP expression levels decreased at an equal rate. Additionally, SLAM and SAP expression levels were negatively correlated with the serum IgE levels in AR patients (Figure 1 $\mathrm{J}$ and $\mathrm{K}$ ).

A

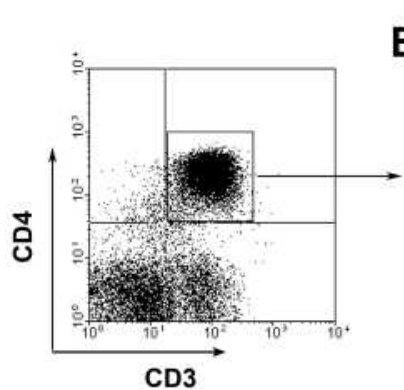

B
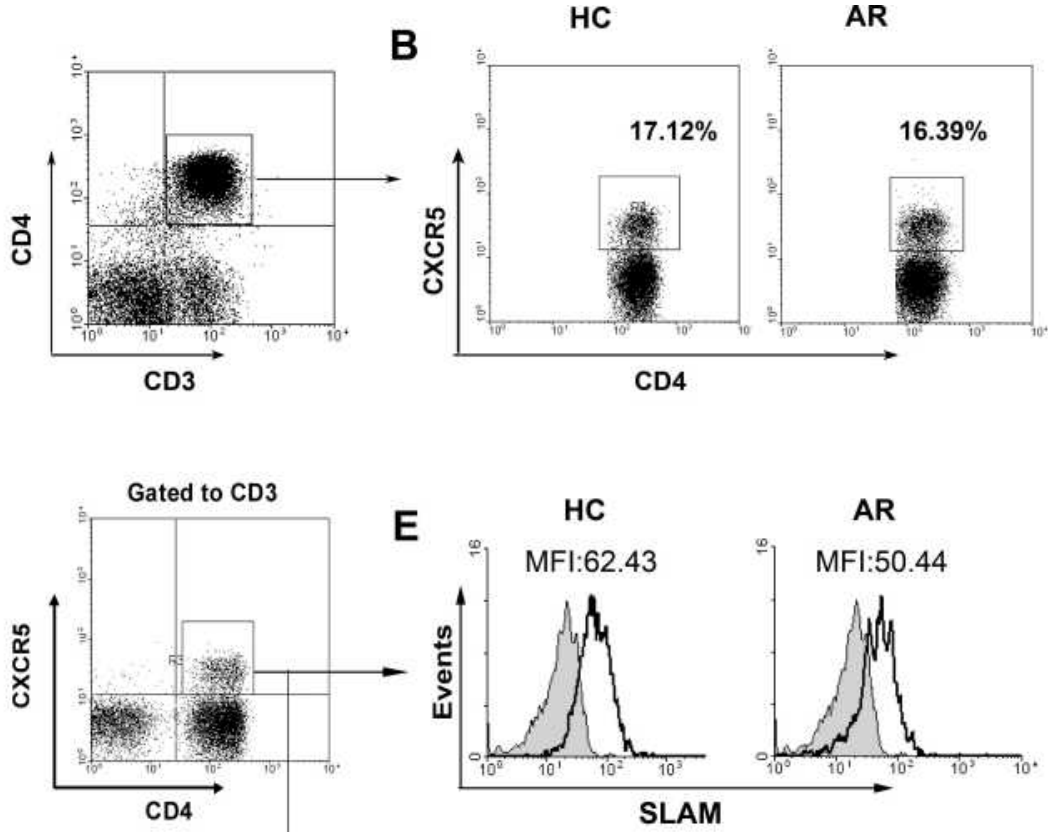

E
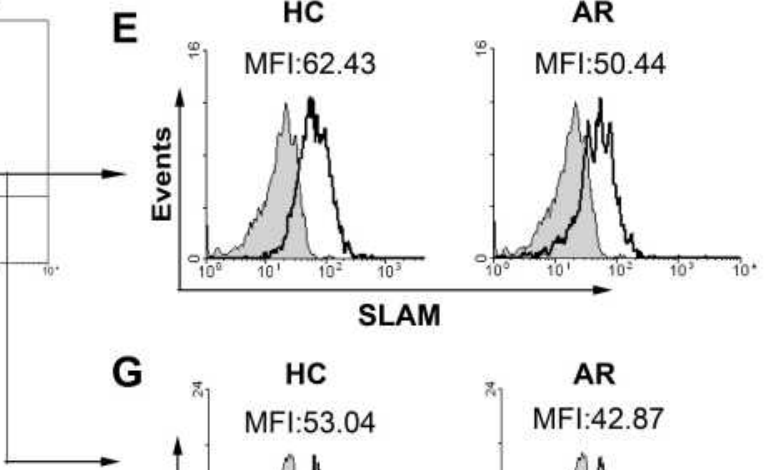

G
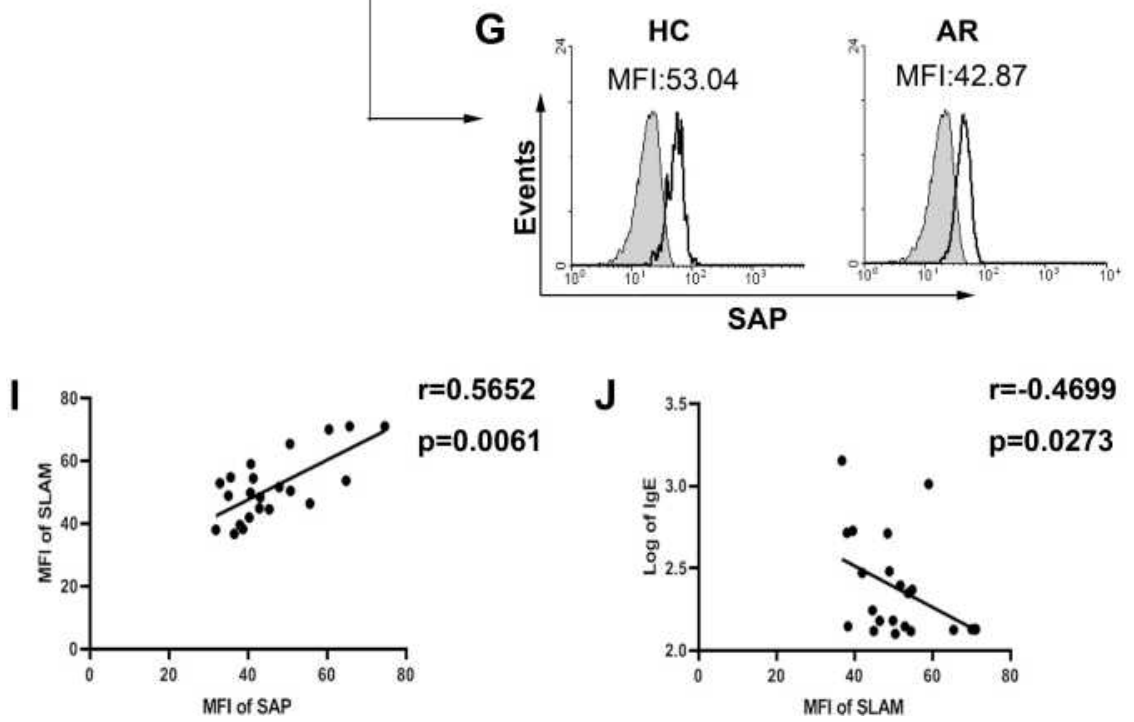

$\mathbf{F}$
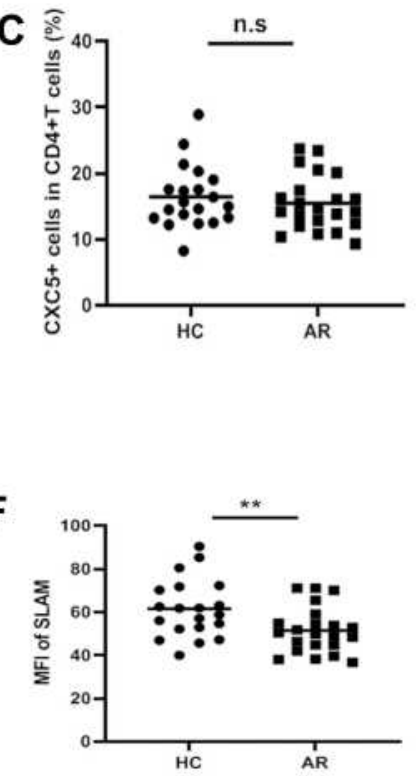

H
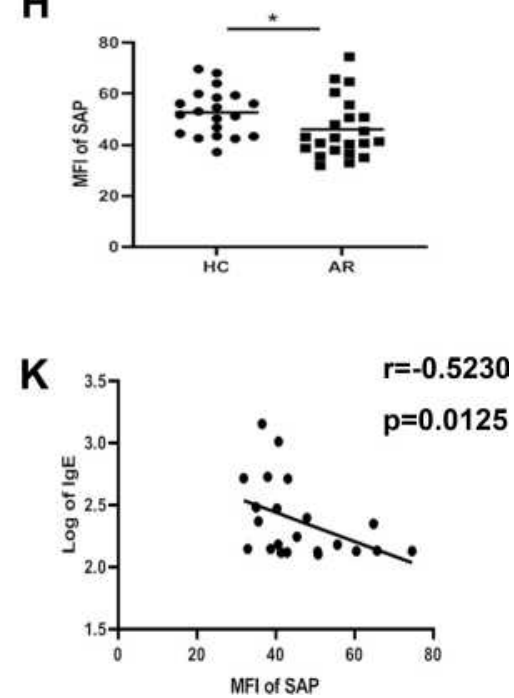

Figure I Expression of SLAM/SAP in CD4 ${ }^{+} \mathrm{CXCR5^{+ }}$ T cells in AR patients. (A and B) Gating strategy and representative flow plot. (C) Frequencies of CXCR5 ${ }^{+}$cells among CD4 $4^{+}$T cells within PBMCs. (D) Detection of SLAM/SAP expression was gated on $C D 3^{+} C D 4^{+} C X C R 5^{+} T$ cells. (E) Representative SLAM plot. (F) The expression of SLAM. (G) Representative plot of SAP. (H) The expression of SAP. (I) The correlation between the expression of SLAM and SAP in CD $4^{+} C X C R 5^{+}$T cells from AR patients. (J) The correlation between the expression of SLAM and IgE in AR patients. (K) The correlation between the expression of SAP and IgE in AR patients. $* P<0.05$; $* * P<0.01$. 


\section{High Levels of IL-2I in AR Patients}

As a functional cytokine of Tfh cells, IL-21 has the most potent capacity to drive plasma cell differentiation. Notably, the IL-21 levels in serum were significantly increased in AR patients (Figure 2A), and a positive correlation was found between IL-21 and $\mathrm{IgE}$ expression (Figure 2B). Interestingly, we found a negative correlation between the IL-21 level and SLAM or SAP expression in $\mathrm{CD}^{+} \mathrm{CXCR}^{+} \mathrm{T}$ cells (Figure $2 \mathrm{C}$ and $\mathrm{D}$ ).

\section{SLAM Stimulation Reduced IL-2 I Production in $\mathrm{CD} 4^{+} \mathrm{CXCR5^{+ }}$ Tfh-Like Cells}

Because the data shown above indicated that serum IL-21 levels were negatively correlated with SLAM expression on $\mathrm{CD}^{+} \mathrm{CXCR}^{+} \mathrm{T}$ cells, we aimed to determine whether SLAM expression on $\mathrm{CD} 4^{+} \mathrm{CXCR} 5^{+} \mathrm{T}$ cells contributed to the reduced production of $\mathrm{IL}-21 . \mathrm{CD}^{+} \mathrm{CXCR}^{+}$cells were isolated from PBMCs (Figure 3A) and stimulated with anti-SLAM mAb. A significant decrease in IL-21 production was observed compared with that of control IgG (Figure 3B). The experiment showed that the change occurred after $48 \mathrm{~h}$ (Figure 3C) and was dose-dependent to some extent (Figure 3D).

\section{Decreased SLAM Expression on $\mathrm{CD} / 9^{+}$ $B$ Cells in AR Patients}

As B cells and Tfh cells are the most important cells that participate in humoral immunity, their development is tightly interrelated. B cells can not only receive signals from Tfh cells to differentiate into plasma cells to produce immunoglobulin but can also deliver signals to Tfh cells as APCs. SLAM can homotypically bind and function as a costimulatory molecule ${ }^{22,23}$ and can be expressed on the surfaces of both $\mathrm{T}$ and $\mathrm{B}$ cells. Therefore, we further explored the changes in B cells. As shown in Figure 4A and $\mathrm{B}$, we observed an increased percentage of $\mathrm{B}$ cells in patients with AR. However, expression of SLAMs on the $\mathrm{B}$ cell surface was decreased in AR patients compared to that in healthy controls (Figure $4 \mathrm{C}$ and D).

\section{Discussion}

The dysregulation of Th1/Th2 cells has predominated in investigations of the mechanism of allergic disease over the past 20 years. We sought to add an additional layer of complexity to the regulation of allergic inflammation. Recently, an increasing number of studies have reported that the frequencies of circulating Tfh cells are increased in autoimmune diseases, which is accompanied by high
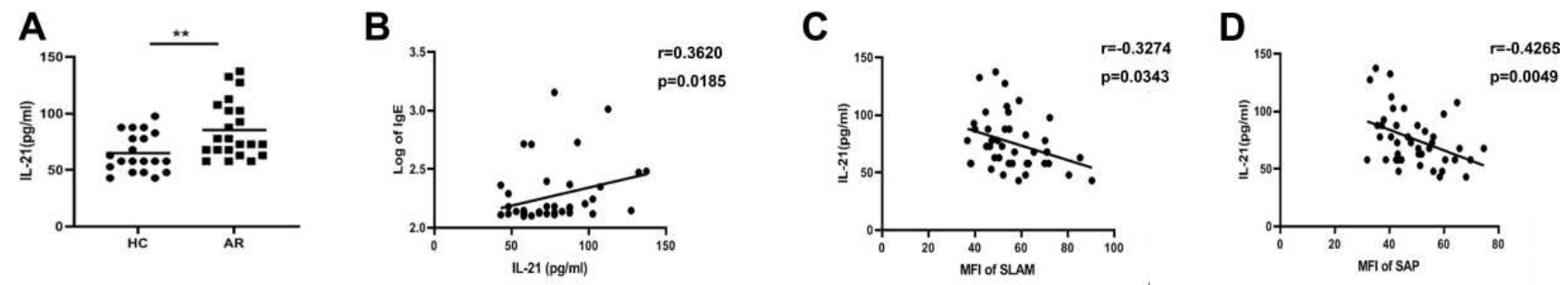

Figure 2 High levels of IL-2I in AR patients. (A) Level of serum IL-2I. (B) The correlation between serum IL-2I and IgE. (C) The correlation between SLAM and IL-2I. (D) The correlation between SAP and IL-2I. $* * P<0.01$.
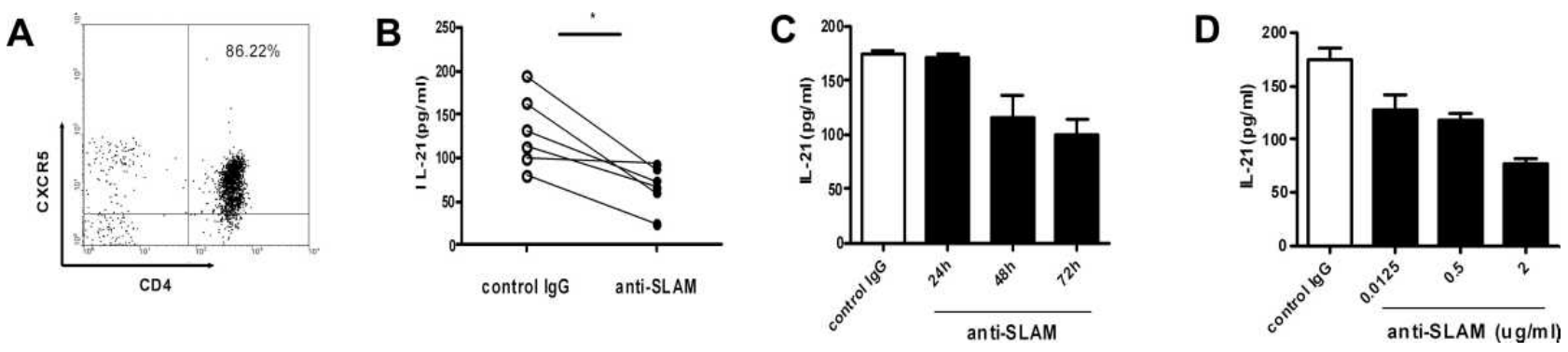

Figure 3 SLAM reduced the production of IL-2I in CD4 ${ }^{+} \mathrm{CXCR5}{ }^{+} \mathrm{T}$ cells. (A) The purity of $\mathrm{CD} 4^{+} \mathrm{CXCR} 5^{+}$cells was analyzed by FCM. (B) The levels of IL-2I secreted by $\mathrm{CD}^{+} \mathrm{CXCR}^{+} \mathrm{T}$ cells with anti-SLAM mAb stimulation $(0.5 \mu \mathrm{g} / \mathrm{mL}, 48 \mathrm{~h}, \mathrm{n}=6)$. (C and D) The levels of IL-2I secreted by CD4 ${ }^{+} \mathrm{CXCR5^{+ }}$ T cells after anti-SLAM stimulation at different time points or at different concentrations. $* P<0.05$. 
A

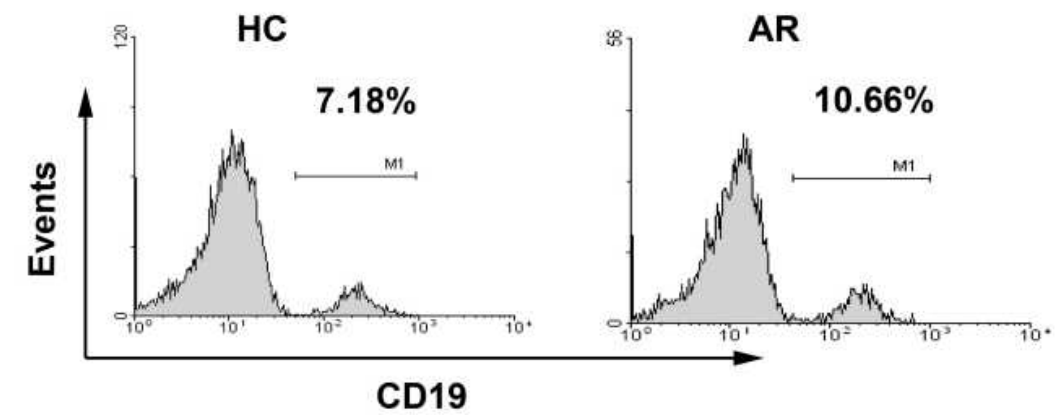

C

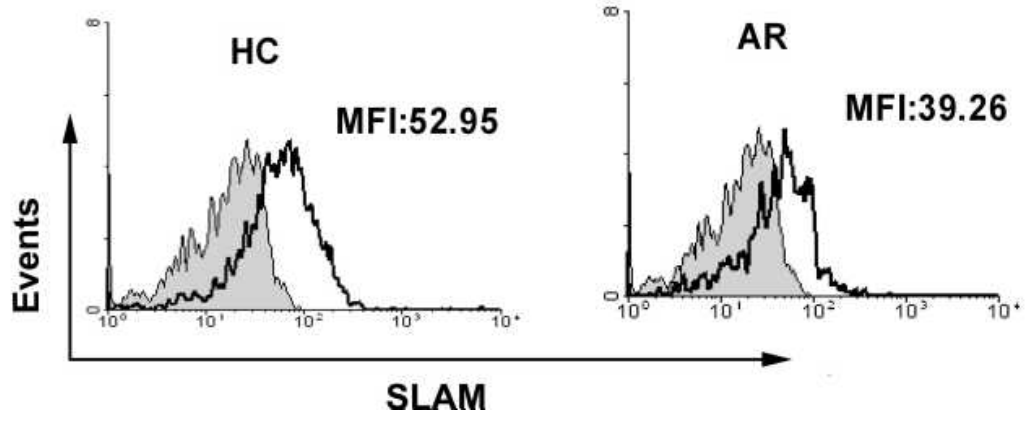

B

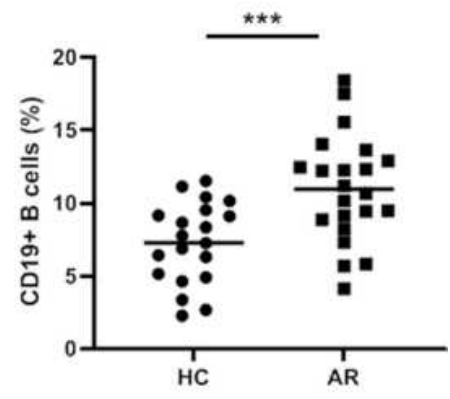

D

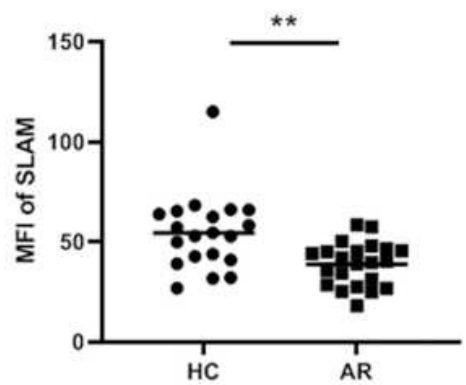

Figure 4 Expression of SLAM on the B cell surface in AR patients. (A) Representative flow plot of CDI9 $9^{+}$cells. (B) Frequencies of CDI9+ $B$ cells in PBMCs. (C) Representative plot of SLAM. (D) The expression of SLAM on the CDI $9^{+}$B cell surface. $* * P<0.01$; $* * * P<0.00$ I.

levels of IL-21 and autoantibodies. However, the role of $\mathrm{Tfh}$ cells in IgE-mediated diseases is not well understood.

In the present study, we found no significant differences in the percentages of circulating $\mathrm{CD} 4^{+} \mathrm{CXCR}^{+}{ }^{+}$Tfh-like cells in peripheral blood between AR patients and healthy controls. This might be due to the predominately localized immune response in AR patients. Recently, Zhang et al confirmed that $\mathrm{CD} 4^{+} \mathrm{CXCR}^{+}{ }^{+} \mathrm{Tfh}$ cells accumulated and expanded in nasal polyp tissue and could promote $\mathrm{IgG}$, IgA, and $\operatorname{IgE}$ production by naive $\mathrm{B}$ cells, and this could be blocked by depletion of IL-21 to some extent. ${ }^{24}$ Blood $\mathrm{CD}^{+}{ }^{+} \mathrm{CXCR} 5^{+}$Tfh-like cells were shown to be circulating and to not fully reflect the local immunity. Another explanation is that blood $\mathrm{CD} 4^{+} \mathrm{CXCR} 5^{+} \mathrm{T}$ cells are Tfh-like cells, comprising a group of mixed cells. They were suggested to be resting cells with a memory phenotype. ${ }^{25}$ Only a small proportion of blood $\mathrm{CD} 4^{+} \mathrm{CXCR} 5^{+} \mathrm{T}$ cells expressed the activation molecules (ICOS and CD69) that are expressed by conventional follicular Tfh cells. He et $\mathrm{al}^{26}$ proposed that circulating Tfh cells can be categorized as effector memory cells (Tfh-em) and central memory cells (Tfh-cm) on the basis of PD-1 and CCR7 expression. Tfh-em cells are defined as $\mathrm{PD}-1^{+} \mathrm{CXCR} 5^{+} \mathrm{BCL} 6{ }^{-} \mathrm{ICOS}^{+} \mathrm{CCR} 7^{\text {low }}$ cells, which are similar to pre-Tfh cells at the activated stage, and Tfh-cm cells are PD- $1^{-} \mathrm{CXCR} 5^{+} \mathrm{BCL}^{-}{ }^{-} \mathrm{ICOS}^{-} \mathrm{CCR} 7^{+}$ cells that can persist for weeks after antigen stimulation. Tfh-em cells may represent the most potent helper cells among circulating Tfh cells. It may be interesting to detect changes in Tfh-em and Tfh-cm cells in AR patients. Therefore, additional molecular markers could be used to define Th cells more precisely. The percentages of $\mathrm{CD}^{+} \mathrm{CXCR}^{+} \mathrm{T}$ cell subsets might affect the severity of AR. One recent study demonstrated that circulating $\mathrm{CD}^{+} \mathrm{CXCR}^{+} \mathrm{T}$ cells can be defined as three subsets according to their differential expression of CXCR3 and CCR6. ${ }^{10} \mathrm{CXCR}^{+}{ }^{+} \mathrm{CC} 6{ }^{-}$(Tfh1) cells secrete IFN- $\gamma$ and express T-bet. $\mathrm{CXCR}^{-}{ }^{-} \mathrm{CC} 6^{-}$(Tfh2) cells produce IL-4, IL-5, and IL-13 and express GATA-3. CXCR3 $3^{-} \mathrm{CC}^{+}$ (Tfh17) cells produce IL-17A and IL-22 and express RORyt. Only Th2-like CXCR5 ${ }^{+}$T cells $\left(\mathrm{CXCR}^{-}{ }^{-} \mathrm{CCR} 6^{-}\right)$ could induce naive B cells to produce IgE. Kamekura et al showed that the percentage and number of Tfh1 cells $\left(\mathrm{CD}^{+} \mathrm{CXCR}^{+} \mathrm{CXCR}^{+} \mathrm{CC}^{-}\right)$were decreased and $\mathrm{Tfh} 2$ cells $\left(\mathrm{CD}^{+} \mathrm{CXCR}^{+} \mathrm{CXCR}^{-} \mathrm{CC}^{-}\right)$were significantly 
increased in AR patients. ${ }^{4}$ The Tfh17 subset was unchanged. In addition to these cells, another subset called Tfr cells, which were identified as CD $45^{+}$CD $45 \mathrm{RA}^{\text {low }} \mathrm{CXCR}^{+} \mathrm{CD} 25^{\text {high }} \mathrm{CD} 127^{\text {low }} \mathrm{Foxp}^{+}$ $\mathrm{T}$ cells, was found to be defective in AR patients. ${ }^{27}$ Detecting changes in subsets of Tfh cells could be meaningful.

Next, we documented that $\mathrm{CD} 4^{+} \mathrm{CXCR} 5^{+} \mathrm{T}$ cells in $\mathrm{AR}$ patients displayed decreased expression of the surface molecules SLAM and SAP. The decreased degree of SLAM and SAP expression reflected the disease severity to some extent by being negatively correlated with serum IgE. Since SLAM was expressed at higher levels on Th1 cells than on Th 2 cells and could induce IFN- $\gamma$ production ${ }^{28}$ it was used as a marker of the Th2 to Th1 shift. Previous studies showed increased SLAM expression in Th1predominant autoimmune diseases, such as multiple sclerosis $^{19}$ and rheumatoid arthritis. ${ }^{29}$ Additionally, diminished expression of allergen-induced SLAM mRNA in PBMCs was observed in AR, and SLAM expression was recovered after specific immunotherapy (SIT). ${ }^{13}$ These reports supported our observation of decreased expression of SLAMs on $\mathrm{CD}^{+} \mathrm{CXCR}^{+}$Tfh-like cells in AR patients.

We also discovered decreased expression of SLAMs on $B$ cells and an equal decrease in the expression of both SLAM and SAP on $\mathrm{CD}^{+} \mathrm{CXCR}^{+}$Tfh-like cells. Both SAP and SLAMs are recruited to the immunological synapse after stimulation, where T cells and APCs come into contact. SAP can bind to the ITSM in the cytoplasmic domains of a SLAM to form and maintain T-B conjugates and can modulate the crosstalk between SLAMs and TCRs. Here, we propose a mechanism for this action: a SLAM primarily allows Tfh cells to adhere to B cells, and $\mathrm{Tfh}$ cell differentiation is induced by signals conveyed by $\mathrm{B}$ cells that sustain prolonged T-B conjugation times via SAP-dependent SLAM adhesion. Our observations suggested that a decrease occurred in the formation of Tfh-B conjugates of SLAM-SLAM-SAP, indicating a change in the signal passed between Tfh cells and $B$ cells. Interestingly, a recent study showed that SLAMF1 engagement can diminish IL-6 and IgG production by $\mathrm{B}$ cells and inhibit $\mathrm{B}$ cell differentiation toward plasmablasts. Because of a lack of SAP in B cells, this effect may occur in an SHP-2-dependent manner. ${ }^{30}$ Therefore, decreased SLAM expression may also promote B cell differentiation toward Ig-secreting plasma cells, except in the case of $\mathrm{Tfh}$ cell regulation. Thus, the SLAM signal may bidirectional.
Furthermore, we detected the most functional cytokine of Tfh cells. The IL-21 level was significantly increased in AR patients and positively correlated with IgE. The role of IL-21 in IgE-mediated allergic diseases remains enigmatic, as conflicting results have been reported thus far. Salzer et al reported that homozygous loss-of-function mutations in the IL-21 gene were associated with reduced numbers of $\mathrm{CD}^{+}{ }^{+} \mathrm{B}$ cells and decreased serum IgG levels but an increased IgE concentration. ${ }^{31}$ However, some in vitro experiments have shown that IL-21 enhances the production of $\operatorname{IgE}$ and promotes the proliferation of $\mathrm{CD}^{+} 9^{+}$ B cells when they are stimulated with anti-CD40 and IL4 or IL-13. ${ }^{32}$ These discrepancies might be due to the pleiotropic effects of IL-21 and the complexity of the immune environment in vivo. Here, we speculate that high levels of serum IL-21 lead to high levels of $\operatorname{IgE}$, which predominate type 2 immunity, in AR and that the Th2 cytokines IL-4 and IL-13 also show high concentrations. In addition to high IL-21 levels in serum, a previous study indicated that allergic asthma patients had higher frequencies of $\mathrm{IL}-21^{+} \mathrm{CD} 4^{+} \mathrm{CXCR} 5^{+} \mathrm{T}$ cells. ${ }^{33}$ Here, we speculated that $\mathrm{CD} 4^{+} \mathrm{CXCR} 5^{+}$Tfh-like cells in $\mathrm{AR}$ patients could be more capable of producing IL-21, although the percentages of $\mathrm{CD}^{+} \mathrm{CXCR}^{+}$Tfh-like cells were not different.

Because the decreased expression of SLAMs and SAP was negatively correlated with the enhanced expression of serum IL-21, we examined the influence of SLAM on IL-21 production by $\mathrm{CD} 4^{+} \mathrm{CXCR} 5^{+} \mathrm{T}$ cells. We observed that the engagement of SLAM resulted in a significant decrease in IL-21 expression in $\mathrm{CD}^{+} \mathrm{CXCR}^{+} \mathrm{T}$ cells. This reduction in expression occurred at $48 \mathrm{~h}$ after stimulation and was maintained for $72 \mathrm{~h}$, which revealed the prolonged effects. Downregulation of IL-21 occurred in a dose-dependent manner; stronger stimulation by SLAM resulted in greater reduction in the expression of IL-21. Conversely, insufficient/weak stimulation of $\mathrm{CD}^{+} \mathrm{CXCR}^{+}$Tfh-like cells by SLAM resulted in increased IL-21 production. This finding was consistent with our observation of decreased expression of SLAMs and high levels of IL-21 in AR patients. Therefore, we speculated that the low SLAM expression on $\mathrm{CD}^{+} \mathrm{CXCR}^{+}$Tfh-like cells might contribute to the high levels of serum IL-21 in AR patients. Regrettably, there was the limitation that the purity of $\mathrm{CD}^{+} \mathrm{CXCR}^{+}$cells from human PBMC using MACS method was only more than $85 \%$ which due to twice separations. Small portions of $\mathrm{CD}^{+} \mathrm{CXCR}^{-}$cells, like Th17 cells, can also produce IL21. However, the frequencies of $\mathrm{CD} 4^{+} \mathrm{IL}-17^{+}$Th17 cells 
were less than $5 \%$ in healthy individuals. The impact of this factor on our results is limited. Additionally, we reported increased percentages of $\mathrm{B}$ cells. Meanwhile, Hsiao-Yu et al observed high expression of IL-21 receptor on naive and memory B cells in AR patients. ${ }^{34}$ This was in line with the high levels of IL-21 and IgE in serum in AR patients. IL21 could drive more $B$ cells to differentiate into plasma cells to secrete immunoglobulin, including IgE, which likely contributes to the pathogenesis of AR.

Based on a literature review, this report takes the initiative to focus on the role of SLAM on $\mathrm{CD}^{+} \mathrm{CXCR}^{+}$Tfh-like cells. Our study provided evidence that decreased SLAM expression on $\mathrm{CD}^{+} \mathrm{CXCR}^{+}$Tfh-like cells might upregulate IL-21 production to contribute to the pathogenesis of AR. However, our data have some limitations. Future studies need to be performed to 1) investigate SLAM expression on $\mathrm{CD}^{+} \mathrm{CXCR}^{+}$Tfh-like cells in different allergic diseases, 2) investigate SLAM expression on $\mathrm{CD} 4^{+} \mathrm{CXCR} 5^{+}$ Tfh-like cells in local tissues, and 3) analyze the involvement of downstream factors that account for SLAMinduced suppression of IL-21 expression. In terms of the value of this research, the data in this study extend the understanding of the pathogenesis of AR and identify a potential biomarker and therapeutic target.

\section{Conclusion}

In this study, we report for the first time that decreased expression of SLAMs on $\mathrm{CD} 4^{+} \mathrm{CXCR} 5^{+} \mathrm{Tfh}$-like cells contributes to enhance IL-21 production in AR patients, which might be further validated as a potential therapeutic strategy.

\section{Abbreviations}

AR, Allergic rhinitis; GC, germinal center; IL-21, interleukin 21; PBMCs, peripheral blood mononuclear cells; SAP, SLAM-associated protein; SLAM, Signaling lymphocytic activation molecule; Tfh, follicular helper T cells; Th, helper T cells.

\section{Funding}

This work was supported by the Jiangsu Province's Key Medical Talents Program (grant nos. ZDRCB2016018 and QNRC2016456).

\section{Disclosure}

The authors report no conflicts of interest in this work.

\section{References}

1. Broide DH. The pathophysiology of allergic rhinoconjunctivitis. Allergy Asthma Pro. 2007;28(4):398-403. doi:10.2500/aap.2007.28.3011

2. Ayelign B, Akalu Y, Teferi B, Molla MD, Shibabaw T. Helminth induced immunoregulation and novel therapeutic avenue of allergy. $J$ Asthma Allergy. 2020;13:439-451. doi:10.2147/JAA.S273556

3. Ciprandi G, Filaci G, Battaglia F, Fenoglio D. Peripheral Th-17 cells in allergic rhinitis: new evidence. Int Immunopharmacol. 2010;10 (2):226-229. doi:10.1016/j.intimp.2009.11.004

4. Kamekura R, Shigehara K, Miyajima S, et al. Alteration of circulating type 2 follicular helper T cells and regulatory $\mathrm{B}$ cells underlies the comorbid association of allergic rhinitis with bronchial asthma. Clin Immunol. 2015;158(2):204-211. doi:10.1016/j.clim.2015.02.016

5. Nurieva RI, Chung Y, Hwang D, et al. Generation of T follicular helper cells is mediated by interleukin-21 but independent of $\mathrm{T}$ helper 1,2 , or 17 cell lineages. Immunity. 2008;29:138-149. doi:10.1016/j.immuni.2008.05.009

6. Linterman MA, Beaton L, Yu D, et al. IL-21 acts directly on B cells to regulate Bcl-6 expression and germinal center responses. $J$ Exp Med. 2010;207:353-363. doi:10.1084/jem.20091738

7. Bryant VL, Ma CS, Avery DT, et al. Cytokine-mediated regulation of human $\mathrm{B}$ cell differentiation into Ig-secreting cells: predominant role of IL-21 produced by CXCR5 + T follicular helper cells. J Immunol. 2007;179:8180-8190. doi:10.4049/jimmunol.179.12.8180

8. Avery DT, Deenick EK, Ma CS, et al. B cell-intrinsic signaling through IL-21 receptor and STAT3 is required for establishing long-lived antibody responses in humans. $J$ Exp Med. 2010;207:155-171. doi:10.1084/jem.20091706

9. Chen J, Tian J, Tang X, et al. MiR-346 regulates CD4+CXCR5 + $\mathrm{T}$ cells in the pathogenesis of Graves' disease. Endocrine. 2015;49:752-760. doi:10.1007/s12020-015-0546-5

10. Morita R, Schmitt N, Bentebibel S, et al. Human blood CXCR5 CD4 $\mathrm{T}$ cells are counterparts of $\mathrm{T}$ follicular cells and contain specific subsets that differentially support antibody secretion. Immunity. 2011;34:108-121. doi:10.1016/j.immuni.2010.12.012

11. Ma J, Zhu C, Ma B, et al. Increased frequency of circulating follicular helper $\mathrm{T}$ cells in patients with rheumatoid arthritis. Clin Dev Immunol. 2012;2012:827480. doi:10.1155/2012/827480

12. Zhu C, Ma J, Liu Y, et al. Increased frequency of follicular helper $\mathrm{T}$ cells in patients with autoimmune thyroid disease. J Clin Endocrinol Metab. 2012;97(3):943-950. doi:10.1210/jc.2011-2003

13. Carballido JM, Aversa G, Kaltoft K, et al. Reversal of human allergic $\mathrm{T}$ helper 2 responses by engagement of signaling lymphocytic activation molecule. J Immunol. 1997;159(9):4316-4321.

14. Sayos J, Wu C, Morra M, et al. The X-linked lymphoproliferative-disease gene product SAP regulates signals induced through the co-receptor SLAM. Nature. 1998;395:462-469. doi:10.1038/26683

15. Crotty S, Kersh EN, Cannons J, Schwartzberg PL, Ahmed R. SAP is required for generating long-term humoral immunity. Nature. 2003;421:282-287. doi:10.1038/nature01318

16. Qi H, Cannons JL, Klauschen F, Schwartzberg PL, Germain RN. SAP-controlled T-B cell interactions underlie germinal centre formation. Nature. 2008;455:764-769. doi:10.1038/nature07345

17. Czar MJ, Kersh EN, Mijares LA, et al. Altered lymphocyte responses and cytokine production in mice deficient in the X-linked lymphoproliferative disease gene SH2D1A/DSHP/SAP. Proc Natl Acad Sci USA. 2001;98:7449-7454. doi:10.1073/pnas.131193098

18. Ma CS, Hare NJ, Nichols KE, et al. Impaired humoral immunity in $\mathrm{X}$-linked lymphoproliferative disease associated with defective IL-10 production by CD4+ T cells. J Clin Invest. 2005;115:1049-1059. doi:10.1172/JCI200523139

19. Ferrante P, Fusi ML, Sarasella M, et al. Cytokine production and surface marker expression in acute and stable multiple sclerosis: altered IL-12 production and augmented signaling lymphocytic activation molecule (SLAM)-expressing lymphocytes in acute multiple sclerosis. J Immunol. 1998;160:1514-1521. 
20. Cannons JL, Yu LJ, Hill B, et al. SAP regulates T(H)2 differentiation and PKC-è-mediated activation of NF-êB1. Immunity. 2004;21:693-706. doi:10.1016/j.immuni.2004.09.012

21. Yusuf I, Kageyama R, Monticelli L, et al. Germinal center $\mathrm{T}$ follicular helper cell IL-4 production is dependent on signaling lymphocytic activation molecule receptor (CD150). J Immunol. 2010;185:190-202. doi:10.4049/jimmunol.0903505

22. Punnonen J, Cocks BG, Carballido JM, et al. Soluble and membrane-bound forms of signaling lymphocytic activation molecule (SLAM) induce proliferation and Ig synthesis by activated human B lymphocytes. $J$ Exp Med. 1997;185:993-1004. doi:10.1084/ jem.185.6.993

23. Mavaddat N, Mason DW, Atkinson PD, et al. Signaling lymphocytic activation molecule (CDw150) is homophilic but self-associates with very low affinity. $J$ Biol Chem. 2000;275:28100-28109. doi:10.1074/ jbc.M004117200

24. Zhang YN, Song J, Wang H, et al. Nasal IL-4+CXCR5+ CD4+ $\mathrm{T}$ follicular helper cell counts correlate with local IgE production in eosinophilic nasal polyps. J Allergy Clin Immunol. 2016;137 (2):462-473. doi:10.1016/j.jaci.2015.07.025

25. Schaerli P, Willimann K, Lang AB, Lipp M, Loetscher P, Moser B. CXC chemokine receptor 5 expression defines follicular homing $\mathrm{T}$ cells with $\mathrm{B}$ cell helper function. $J$ Exp Med. 2000;192:1553-1562. doi:10.1084/jem.192.11.1553

26. He J, Tsai LM, Leong YA, et al. Circulating precursor CCR7(lo)PD-1 (hi) CXCR5(+) CD4(+) T cells indicate Tfh cell activity and promote antibody responses upon antigen reexposure. Immunity. 2013;39 (4):770-781. doi:10.1016/j.immuni.2013.09.007

27. Yao Y, Wang ZC, Wang N, et al. Allergen immunotherapy improves defective follicular regulatory $\mathrm{T}$ cells in patients with allergic rhinitis. $J$ Allergy Clin Immunol. 2019;144:118-128. doi:10.1016/j. jaci.2019.02.008
28. Laaksonen K, Junikka M, Lahesmaa R, Terho EO, Savolainen J. In vitro allergen-induced mRNA expression of signaling lymphocytic activation molecule by PBMC of patients with allergic rhinitis is increased during specific pollen immunotherapy. J Allergy Clin Immunol. 2003;112(6):1171-1177. doi:10.1016/j.jaci.2003.08.043

29. Isomäki $P$, Aversa $G$, Cocks BG, et al. Increased expression of signaling lymphocytic activation molecule in patients with rheumatoid arthritis and its role in the regulation of cytokine production in rheumatoid synovium. J Immunol. 1997;159:2986-2993.

30. Karampetsou MP, Comte D, Suárez-Fueyo A, et al. Signaling lymphocytic activation molecule family member 1 engagement inhibits T cell-B cell interaction and diminishes interleukin- 6 production and plasmablast differentiation in systemic lupus erythematosus. Arthritis Rheumatol. 2019;71:99-108. doi:10.1002/art.40682

31. Salzer E, Kansu A, Sic H, et al. Early-onset inflammatory bowel disease and common variable immunodeficiency-like disease caused by IL-21 deficiency. J Allergy Clin Immunol. 2014;133:1651-1659. doi:10.1016/j.jaci.2014.02.034

32. Wood N, Bourque K, Donaldson DD, et al. IL-21 effects on human IgE production in response to IL-4 or IL-13. Cell Immunol. 2004;231:133-145. doi:10.1016/j.cellimm.2005.01.001

33. Gong F, Zhu HY, Zhu J, Dong Q, Huang X, Jiang D. Circulating $\mathrm{CD}^{+} \mathrm{CXCR}^{+} \mathrm{T}$ cells participate in the IgE accumulation in allergic asthma. Immunol Lett. 2018;197:9-14. doi:10.1016/j. imlet.2018.03.001

34. Jen HY, Yang YH, Chiang BL, et al. Upregulated interleukin-21 receptor on $\mathrm{B}$ cells associated with the downregulation of IgE in patients with allergic rhinitis. $J$ Interferon Cytokine Res. 2015;35:42-48. doi:10.1089/jir.2014.0036

\section{Publish your work in this journal}

The Journal of Asthma and Allergy is an international, peer-reviewed open-access journal publishing original research, reports, editorials and commentaries on the following topics: Asthma; Pulmonary physiology; Asthma related clinical health; Clinical immunology and the immunological basis of disease; Pharmacological interventions and new therapies. The manuscript management system is completely online and includes a very quick and fair peer-review system, which is all easy to use. Visit http://www.dovepress.com/testimonials.php to read real quotes from published authors. 